\title{
Effect of universal adhesives on microtensile bond strength to hybrid ceramic
}

Mohamed M. Awad ${ }^{1}$, Lamees Albedaiwi ${ }^{2}$, Ahmed Almahdy ${ }^{3}$, Rawaiz Khan ${ }^{4}$, Nick Silikas ${ }^{5}$, Muhanad M. Hatamleh ${ }^{6}$, Fahad M. Alkhtani ${ }^{7}$ and Ali Alrahlah ${ }^{8,4^{*}}$ (D)

\begin{abstract}
Background: The aim of this study was to evaluate the effect of universal adhesives (UA) and silane on the microtensile bond strength ( $\mu \mathrm{TBS}$ ) of resin cement to a hybrid ceramic Vita Enamic (VE).

Methods: VE specimens were acid etched using hydrofluoric acid (HF) and were assigned to three groups $(n=10)$ based on the applied bonding technique. In group 1 (S), a silane-based primer was used as a surface treatment prior to the application of a resin cement (Variolink Esthetic DC). In group 2, a silane-containing UA, Clearfil Universal Bond (CUB) was used for the surface treatment, and in group 3, A silane-free UA, Tetric N-Bond Universal (TNU) was used for surface treatment. Resin cement build-ups were prepared. The bonded specimens were sectioned into resin-ceramic beams. Half of the beams of each group were stored for $24 \mathrm{~h}$ at $37^{\circ} \mathrm{C}$ and the other half were subjected to a thermo-cycling aging. The microtensile bond strength ( $\mu$ TBS) was measured at a crosshead speed of $0.5 \mathrm{~mm} / \mathrm{min}$. Failure modes were assessed accordingly. Data were analyzed using a) two-way analysis of variance ANOVA followed by one-way ANOVA and Tukey tests between groups and b) independent $t$-test to detect differences $(a=0.05)$ for each group. The surface topographies of the ceramic surface were evaluated using scanning electron microscopy.
\end{abstract}

Results: The results showed that silane-based primer $(S)$ application resulted in significantly higher $(p<0.05) \mu$ TBS values after $24 \mathrm{~h}$ and after thermocycling compared to both silane-containing UA (CUB) and silane-free UA (TNU). The $\mu$ TBS values of all groups were significantly reduced after thermocycling. No statistically significant difference was observed between the $\mu$ TBS of CUB and TNU after $24 \mathrm{~h}$. However, TNU showed significantly higher $\mu$ TBS after thermocycling. Different failure modes were observed, and adhesive failure was the most common in all groups. Marked surface topographic changes were observed following HF etching.

Conclusion: It is concluded that, the UAs tested cannot be recommended as substitutes to the silanization of Hybrid ceramic.

Keywords: Universal adhesive, Ceramic, Bond strength, Silanization

\footnotetext{
* Correspondence: aalrahlah@ksu.edu.sa

${ }^{8}$ Department Of Restorative Dental Sciences, College of Dentistry, King Saud

University, Riyadh 11545, Saudi Arabia

${ }^{4}$ Engineer Abdullah Bugshan research chair for Dental and Oral

Rehabilitation, King Saud University, Riyadh 11545, Saudi Arabia

Full list of author information is available at the end of the article
}

(c) The Author(s). 2019 Open Access This article is distributed under the terms of the Creative Commons Attribution 4.0 International License (http://creativecommons.org/licenses/by/4.0/), which permits unrestricted use, distribution, and reproduction in any medium, provided you give appropriate credit to the original author(s) and the source, provide a link to the Creative Commons license, and indicate if changes were made. The Creative Commons Public Domain Dedication waiver (http://creativecommons.org/publicdomain/zero/1.0/) applies to the data made available in this article, unless otherwise stated. 


\section{Background}

Dental ceramic materials are widely applied in indirect esthetic restorations using computer-aided design and computer-aided manufacturing (CAD/CAM) technology $[1,2]$. From the material prescriptive, dental ceramics have recently been classified into three main categories: glass-ceramics; polycrystalline ceramics; and resinmatrix ceramics, also known as hybrid ceramics (HCs) [3]. Vita Enamic (VE), Vita Zahnfabrik; Bad Säckingen, Germany, is one example of HCs. VE consists of inorganic phase and organic phase, in which a dominant ceramic network is reinforced by an acrylic polymer network resin, with both networks fully penetrating into one another [4]. HC restorations have shown promising performances in in-vitro [5-9] and clinical studies [10].

Reliable bonding is essential for the long-term clinical success of ceramic restorations [11, 12]. This bonding can be affected by the surface treatment of the ceramic substrate [13], and the chemistry of the selected adhesive [14]. Surface treatments of dental ceramics depend on their compositions [15]. For glass-ceramics restorations, it is recommended to etch the intaglio surface using hydrofluoric acid (HF) to create surface micro irregularities [16, 17], before the application of the 3-methacryloxypropyltrimethoxysilane (silane)based primer which can enhance the physical and chemical bonding between the glass-ceramics and methacrylate-based resin materials such as resin cements [18]. The adhesive strategy of glass-ceramics is applied to HCs.

Universal adhesives (UAs) are the latest category of dental adhesives [19]. The majority of commercial UAs contain 10-methacryloyloxydecyl dihydrogen phosphate (MDP), however a few contain both MDP and silane. UAs are claimed to promote bonding to dental substrates including various ceramics. UAs enhanced the bonding to polycrystalline ceramics such as zirconia because of the presence of MDP [20-22], and showed promising results towards the improvement the bonding strength to indirect resin-based composite [23]. By contrast, with regard to glass-ceramics such as Lithium disilicate ceramic, the application of UAs has failed to replace the silane-based primer $[23,24]$. Currently, there is a lack of information regarding the effectiveness of UAs as substitutes to the silane-based primer, specifically with respect to the bonding of HCs. Therefore, the objective of this study was to investigate the effect of UAs, as substitutes to the silane-based primer application, on microtensile bond strength $(\mu \mathrm{TBS})$ of the resin cement to the $\mathrm{VE}$, and to evaluate the surface topography of VE after HF etching. The null hypotheses were as follow 1) there is no difference in the $\mu$ TBS of the resin cement to the VE following the application of silanebased primer or UAs at $24 \mathrm{~h}$ and after thermocycling, and 2 ) there is no difference in $\mu$ TBS following the application of silane-containing or silane-free UAs at $24 \mathrm{~h}$ and after thermocycling.

\section{Methods}

The materials used in this study and their specifications are summarized in Table 1. Thirty Vita Enamic $\odot$, Vita Zahnfabrik, Bad Säckingen, Germany (VE) blocks (with dimensions of $6 \times 6 \times 6 \mathrm{~mm}^{3}$ ) were made using a lowspeed cutting machine (Isomet, Buehler Ltd., USA), with a 4-in. circular diamond wheel (MetLab Technologies Limited, UK) and water coolant. The blocks were cleaned ultrasonically in distilled water for $5 \mathrm{~min}$ and the top surface of each block was standardized using \#600 silicon carbide papers (CrbiMet Abrasive Disks, Buehler, Lake Bluff, IL, USA) on a $300 \mathrm{rev} / \mathrm{min}$ grinding machine (Automata, Jean Wirtz, Dusseldorf, Germany) for $1 \mathrm{~min}$, followed by a) ultrasonic cleaning in distilled water for $5 \mathrm{~min}$ using an ultrasonicator (Sonicer, Yoshida Dental Manufacturing. Co., Ltd., Tokyo, Japan), and b) air-dring.

\section{Bonding procedure}

The HF (4.6\%) acid was applied to the top surface of the prepared VE blocks using a plastic application tip for 60 s to create an etched surface. Etched surfaces were then washed using water for $30 \mathrm{~s}$ and then air-dried until no moisture was visible. The VE blocks were randomly allocated into three experimental groups $(n=10)$ based on the bonding technique used. In group $1(\mathrm{~S})$, a silanebased primer (Silane, Pulpdent Corporation, Watertown, $M A, U S A$ ) was applied to the etched VE using a microbrush, let evaporate for $1 \mathrm{~min}$, and blown with gentle air stream until it was completely dried. In group 2 , a silane-containing UA, Clearfil Universal Bond (CUB) (Kuraray Noritake Dental Inc., Japan), was mixed with Clearfil DC Activator (Kuraray Noritake Dental Inc., Japan) according to manufacturer instructions, and used for surface treatment. In group 3; A silane-free UA, Tetric N-Bond Universal (TNU), (Ivoclar Vivadent, Schaan, Liechtenstein), was used as a surface treatment. Both UAs were rubbed on the VE surface for 20s, and were air-dried until a glossy, immobile film layer is formed. However, light-curing of UAs was avoided.

Following the use of Silane and UAs, dual-cure resin luting cement (Variolink esthetic DC, Ivoclar Vivadent, Schaan, Liechtenstein) build-ups were prepared. Resin cement was applied incrementally and was adapted using a silicon mold $(6 \times 6 \times 12 \mathrm{~mm})$, which matched the dimensions of VE blocks, thus, a $6 \times 6 \times 6 \mathrm{~mm}^{3}$ resin cement build-up was allowed on the top surface on each of the VE blocks. Each resin cement increment was light cured for 40s using a light emitting diode light curing unit (Bluephase ${ }^{\circ}$, Ivoclar Vivadent, Austria) operated at a light irradiance of $1000 \mathrm{~mW} / \mathrm{cm}^{2}$ as measured using a digital radiometer (Bluephase Meter, Ivoclar Vivadent, Austria). Moreover, to ensure adequate polymerization, additional light curing was performed at four different 
Table 1 Materials composition and supplier's details

\begin{tabular}{|c|c|c|c|}
\hline Material & Brand name, manufacturer and LOT number & Composition & Instructions of use \\
\hline $\begin{array}{l}\text { Hybrid } \\
\text { ceramic }\end{array}$ & $\begin{array}{l}\text { Vita Enamic (VE) } \\
\text { (Vita Zahnfabrik; Bad Säckingen, Germany) } \\
\text { LOT41110 }\end{array}$ & $\begin{array}{l}\mathrm{SiO}_{2}, \mathrm{Al}_{2} \mathrm{O}_{3}, \mathrm{Na}_{2} \mathrm{O}, \mathrm{K}_{2} \mathrm{O}, \mathrm{B}_{2} \mathrm{O}_{3}, \mathrm{ZrO}_{2}, \mathrm{CaO}, \\
\text { UDMA, TEGDMA }\end{array}$ & \\
\hline $\begin{array}{l}\text { Silane-based } \\
\text { primer }\end{array}$ & $\begin{array}{l}\text { Silane (S) } \\
\text { (Silane, Pulpdent Corporation, Watertown, } \\
\text { MA, USA) } \\
02471\end{array}$ & MPS, 2-Propanol & $\begin{array}{l}\text { 1. Apply silane using micro-brush } \\
\text { 2. Let evaporate for } 1 \text { min } \\
\text { 3. Blow with gentle air stream } \\
\text { until completely dry }\end{array}$ \\
\hline $\begin{array}{l}\text { Ceramic } \\
\text { etchant }\end{array}$ & $\begin{array}{l}\text { IPS Ceramic (Ivoclar Vivadent, Schaan, } \\
\text { Liechtenstein) } \\
\text { U39349 }\end{array}$ & 4.6\% Hydrofluoric acid & \\
\hline \multirow[t]{2}{*}{$\begin{array}{l}\text { Universal } \\
\text { adhesives }\end{array}$} & $\begin{array}{l}\text { Clearfil Universal Bond (CUB) } \\
\text { (Kuraray Noritake Dental Inc. } \\
\text { Chiyoda Ku, Tokyo, Japan) } \\
000001\end{array}$ & $\begin{array}{l}\text { Bis-GMA, HEMA, ethanol, 10-MDP, } \\
\text { hydrophilic aliphatic dimethacrylate, } \\
\text { colloidal silica, DL camphorquinone, } \\
\text { silane coupling agent, accelerators, } \\
\text { initiators, water }\end{array}$ & $\begin{array}{l}\text { 1. Dispense one drop each of BOND } \\
\text { and "CLEARFIL DC Activator" into a } \\
\text { well of the dispensing dish and mix } \\
\text { them together with the applicator brush. } \\
\text { 2. Apply the mixture then brush and } \\
\text { leave it for } 5 \mathrm{~s} \text {. } \\
\text { 3. Dry by blowing mild air for more than } \\
5 \mathrm{~s} \text { until the adhesive shows no move. }\end{array}$ \\
\hline & $\begin{array}{l}\text { Tetric N-Bond Universal (TNU) } \\
\text { (Ivoclar Vivadent, Schaan, Liechtenstein) } \\
\text { U22452 }\end{array}$ & $\begin{array}{l}\text { MDP, MCAP, HEMA, D3MA water, } \\
\text { ethanol, highly dispersed silicon } \\
\text { dioxide, initiators and stabilizers }\end{array}$ & $\begin{array}{l}\text { 1. Apply and then scrub for at least } 20 \mathrm{~s} \\
\text { 2. Disperse with oil- and moisture-free } \\
\text { compressed air until a glossy, immobile } \\
\text { film layer. }\end{array}$ \\
\hline $\begin{array}{l}\text { Resin } \\
\text { cement } \\
\text { (Dual cure) }\end{array}$ & $\begin{array}{l}\text { Variolink Esthetic DC } \\
\text { Vivadent, Schaan, Liechtenstein) } \\
\text { V19788 }\end{array}$ & $\begin{array}{l}\text { urethane dimethacrylate, methacrylate } \\
\text { monomers, inorganic fillers } \\
\text { (ytterbium trifluoride and spheroid } \\
\text { mixed oxide), Initiators, stabilizers } \\
\text { and pigments }\end{array}$ & $\begin{array}{l}\text { 1. Dispense Variolink Esthetic DC from } \\
\text { the automix syringe } \\
\text { 2. Apply Variolink Esthetic DC directly } \\
\text { to surface treated ceramic material. } \\
\text { 3. Light cure }\end{array}$ \\
\hline
\end{tabular}

directions was carried out for 40s after the mold was removed. The tip of light-curing unit was kept as close as possible (approximately $1 \mathrm{~mm}$ ), and at zero angle without touching the specimens. This bonding procedure was implemented in all the groups by one operator. Specimens were stored in distilled water for $24 \mathrm{~h}$ at $37^{\circ} \mathrm{C}$.

\section{$\mu$ TBS test}

The bonded blocks were vertically sectioned into serial slabs. These were then sectioned into beams with a crosssectional area of $1 \mathrm{~mm}^{2}( \pm 0.1)$, using a low-speed cutting saw with a water-cooled diamond blade. Peripheral beams were not used in this study as the margins of the VE blocks may have been ineffectively acid etched with HF. Specimens from each group were subdivided into two sub-groups. Half of the specimens were tested immediately after $24 \mathrm{~h}$ of storage in distilled water, while the other half was tested after 5000 cycles of thermocycling using thermocycler machine (THE-1100, SD Mechatronik $\mathrm{GmbH}$, Germany). In each cycle, the specimens were placed in a water bath at $55^{\circ} \mathrm{C}$ for $30 \mathrm{~s}$. Subsequently, they were placed in a water bath at $5^{\circ} \mathrm{C}$ for 30 s.

The cross-sectional area of each bonded stick was measured using a digital caliber. The microtensile bond strength ( $\mu$ TBS) test was carried out using a universal testing machine (Instron 5965, Instron Corporation, USA) with a load cell of $5 \mathrm{kN}$ and a cross-speed of 0.5 $\mathrm{mm} / \mathrm{min}$. Tensile stress was applied to bonded beams until failure. The $\mu$ TBS (expressed in $\mathrm{MPa}$ ) was measured by dividing force in Newtons by premeasured surface area in $\mathrm{mm}^{2}$.

After the debonding, fractured beams were vertically mounted onto coded brass stubs, and the failure modes were assessed using a scanning electron microscopy (SEM) (JSM-6360LV, JEOL Ltd., Tokyo, Japan) at $\times 50$ magnification operated at $15 \mathrm{kV}$. The failure modes were classified as follows: adhesive failure, cohesive failure in the ceramic, cohesive failure in the resin-cement, and mixed failure (adhesive failure together with cohesive failure in the cement).

\section{Evaluation of surface topography}

To evaluate the surface morphology of VE, four discs $(6 \times 6 \mathrm{~mm})$ were prepared by cutting the VE blocks. The top surfaces of the VE blocks were standardized and ultrasonically cleaned using the previously mentioned protocol, and then set into two groups $(n=2)$; in the first group (unetched) and the second group (HFetched); in which VE was acid-etched using HF acid as previously described. Specimens of both groups were gold-coated using a sputter coater (fine coat ion sputter JFC-1100, JEOL Ltd., Tokyo, Japan) for $180 \mathrm{~s}$ at $40 \mathrm{~mA}$. The specimens were then mounted onto coded brass stubs and examined using SEM (JSM-6360LV, JEOL 
Ltd., Tokyo, Japan), at $\times 1500$ magnification) operated at $15 \mathrm{kV}$.

\section{Statistical analyses}

The statistical unit of analysis was the block (average of the beams tested). Data were analyzed using two-way analysis of variance ANOVA followed by one-way ANOVA and Tukey's post-hoc tests between groups and with independent $t$-tests to detect differences $(\alpha=0.05)$ for each group.

\section{Results}

The means and standard deviations of the $\mu$ TBS, in $\mathrm{MPa}$, are shown in Table 2. The numbers of beams tested for each group at $24 \mathrm{~h}$ and after thermocycling were (S:45, CUB:44, TNU:43) and (S:44, CUB:43, TNU: 43) respectively. Silane-based primer $(S)$ application resulted in significantly higher $\mu$ TBS values $(p<0.05)$ after $24 \mathrm{~h}(59.14 \pm 3.19 \mathrm{MPa})$ and after thermocycling $(33.18 \pm$ $2.37 \mathrm{MPa}$ ) as compared to silane-containing UA (CUB: $29.66 \pm 1.07 ; \quad 15.76 \pm 1.95 \mathrm{MPa})$ and silane-free UA (TNU: $29.65 \pm 1.21 ; 17.81 \pm 1.19 \mathrm{MPa}$ ). Even though the $\mu$ TBS values of all groups were significantly reduced after thermocycling, there was no statistically significant difference between the bond strength of CUB and TNU after $24 \mathrm{~h}(p>0.05)$. However, TNU yielded significantly higher $\mu$ TBS values compared to CUB after thermocycling $(p<0.05)$. There were statistically significant interactions between the surface treatments and storage times $(p<0.001)$. The frequencies of the failure modes observed are presented in Fig. 1. Adhesive, mixed, and cohesive failure modes were categorized with adhesive interface failure as the most common failure mode detected in all the tested groups at $24 \mathrm{~h}$; (S: $77.5 \%$, CUB: $89.5 \%$, TNU:81.1\%) and after thermocycling (S:66.7\%, CUB:89.2\%, TNU:91.9\%).

Mixed failure (Fig. 2) was the second most common failure pattern in all the groups at $24 \mathrm{~h}$; (S: $17.5 \%$, CUB: 5.3\%, TNU:13.5\%) and after thermocycling (S:23.1\%, CUB: $10.8 \%$, TNU:8.1\%). Cohesive failure in resin cement was detected in all groups at $24 \mathrm{~h}$; (S:5\%, CUB: 2.6\%, TNU: $5.4 \%$ ) and after thermocycling (S:7.6\%, CUB: $0 \%$, TNU:0\%). Cohesive failure in ceramic was the least

Table 2 Mean (Standard Deviation) of $\mu$ TBS values (MPa) of tested groups. The different superscript small letters indicate significant differences between groups in a same column $p<0.05$ * indicated significant differences between storage time for the same group (rows) $p<0.05$

\begin{tabular}{lll}
\hline Group & $\mu$ TBS after 24 h & $\mu$ TBS after thermocycling \\
\hline S & $59.14^{\mathrm{a}}(3.19)$ & $33.18^{\mathrm{a}}(2.37)^{*}$ \\
CUB & $29.66^{\mathrm{b}}(1.07)$ & $15.76^{\mathrm{b}}(1.95)^{*}$ \\
TNU & $29.65^{\mathrm{b}}(1.21)$ & $17.81^{\mathrm{c}}(1.19)^{*}$ \\
\hline
\end{tabular}

frequently detected failure pattern (2.6\%) and was only observed in CUB group at $24 \mathrm{~h}$ and (S) after thermocycling. No pretest failures were detected in all groups.

SEM micrographs ( $\times 1500$ magnification) showed that, the VE samples etched with HF exhibited marked change in surface morphology, higher retentive shadow irregularities and more prominent crystals (Fig. 3b) in comparison to the unetched samples. These revealed smooth and homogenous surface with fewer crystals that were less prominent, and with very less retentive irregularities (Fig. 3a).

\section{Discussion}

The present study investigated the effect of silane-containing and silane-free UAs on the bonding of resin cement to VE. All groups were subjected to HF (4.6\%) etching. HF can be used to dissolve the ceramic glass phase surface via its reaction with silicon dioxide [25]. HF etching results in enlarged surface texture and increased surface micro-irregularities [11, 25-27] increases the surface energy of the ceramic and reduces the contact angle for bonding agents. [28] SEM examinations (Fig. 3b) showed marked changes in surface morphology, increased surface micro-irregularities and randomly distributed micropores after HF etching. Similar features were observed in previous studies $[29,30]$. The silanebased primer was used in group $\mathrm{S}$ as per manufacturer's recommendations. Silane increases the chemical adhesion between the ceramic and resin materials [31, 32]. Silane molecules react with water to form three silanol groups from the corresponding methoxy groups [31]. The silanol groups thereafter react to form a siloxane network with the silica surface. The monomeric ends of the silane molecules react with the methacrylate groups of the resins via a free radical polymerization process [31]. Silane-containing and silane-free UAs were applied in groups CUB and TNU respectively.

The $\mu$ TBS results showed that the application of the silane-based primer resulted in significantly higher mean bond strength compared to the silane-containing UA and silane-free UA at $24 \mathrm{~h}$ and after thermocycling. Therefore, the first hypothesis was rejected. These results may be explained by the lack of chemical adhesion similar to promoted by silane, between the UAs and VE. The $\mathrm{pH}$ of CUB is acidic (2.3) and that may render silane unstable [33]. and less effective for the formation of a strong siloxane network [34]. Moreover, the complex adhesive composition may negatively affect the reaction of silane to the glass-ceramics [35]. Additionally, the high viscosity of the adhesive solution -compared to the silane-based primer- may reduce the penetrative effects of the adhesive on the surface irregularities of the etched ceramic [35]. However, additional studies may be required to confirm this explanation. The MDP content of 


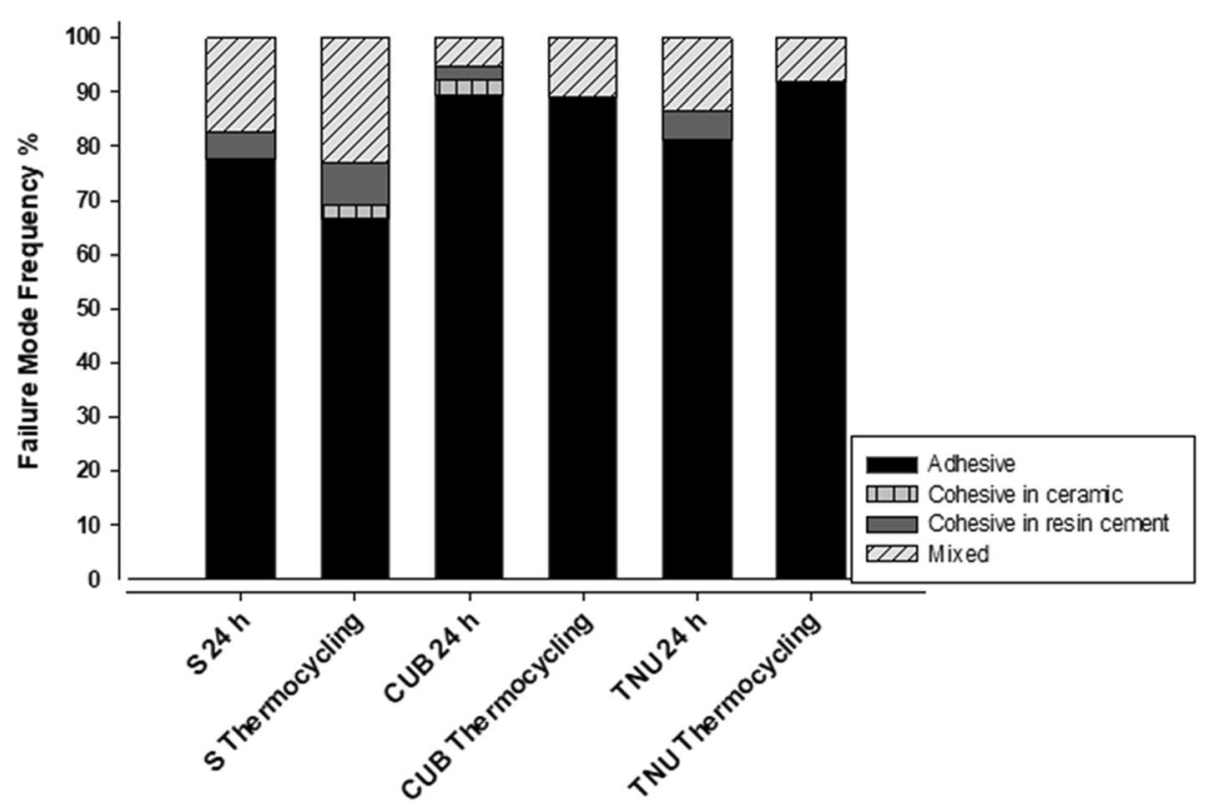

Fig. 1 Frequency (\%) of failure modes observed

both UAs, as well as resin content in VE, did not appear to influence the bonding between UAs and HC. Accordingly, the MDP may not contribute to bonding to the glass- ceramics [34], and the resin content of VE exhibits a higher degree conversion and lacks unreacted monomers. There was no statistically significant difference between the bond strength of CUB and TNU after $24 \mathrm{~h}$. Hence, the second hypothesis was partially rejected.

Different failure modes were observed in this study, with adhesive failure being the most common in all groups. This may be explained by the uniform and homogeneous stress distribution during $\mu$ TBS testing, and the small surface areas of the bonded interfaces (approximately $1 \mathrm{~mm}^{2}$ ) of the tested beams [36]. The

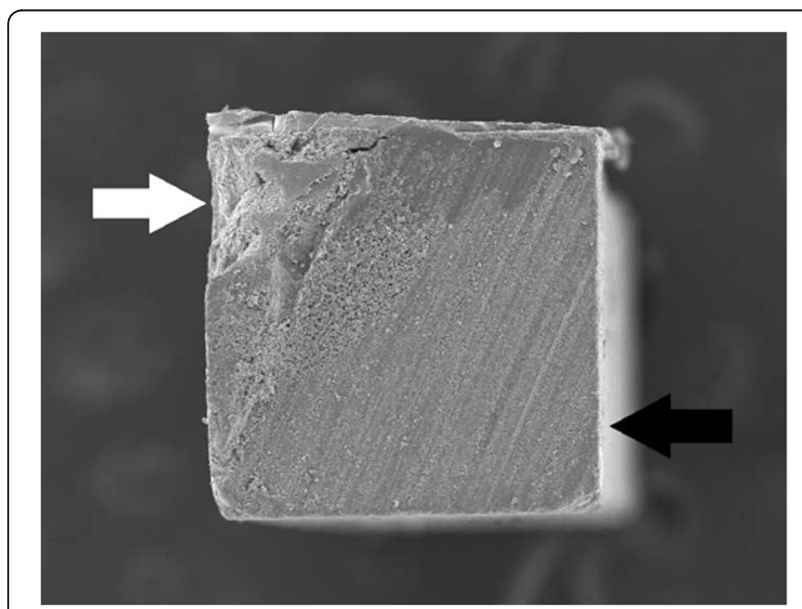

Fig. 2 SEM micrograph ( $\times 50$ magnification) of mixed failure showing resin cement (white arrow) and VE (black arrow) lack of pretest failures in the three experimental conditions may be explained by the adequate $\mu \mathrm{TBS}$ values obtained herein. In part, this relied on the surface microirregularities and topographic changes created (Fig. 3b) following HF etching.

Thermo-cycling procedures for age testing influence the bond strength of bonded materials [37]. The $\mu$ TBS values of all the tested groups were significantly reduced after thermocycling. Water storage and thermocycling both result in the hydrolytic degradation of the ceramic/ resin interface [38]. Thermo-cycling also typically results in combined contraction/expansion stresses and accelerated chemical degradation [39].

Based on the composition similarities, $\mu \mathrm{TBS}$ at $24 \mathrm{~h}$, and the failure modes observed for the two methacrylate-based UAs, it can be assumed that, the use of the same manufacturer UA and resin cement may have a minimal effect on $\mu$ TBS. However, TNU was more resistant compared to CUB, that may be attributed to hydrophobic crosslinking dimethacrylate decandiol dimethacrylate (D3MA). Hydrophobic monomers may be more resistant to degradation and should make the interface more hydrophobic with direct benefit to the bond stability [40].

The results of the present study are in agreement with the findings of previous studies [24], and suggest that the use of a silane-containing UA is not suitable as a substitute for the separate application of silane-based primer. The results of this study are also in accordance with the findings of previous in vitro studies [29, 30, 41, 42] and with recent guidelines published by The International Academy for Adhesive Dentistry [43]. These guidelines 


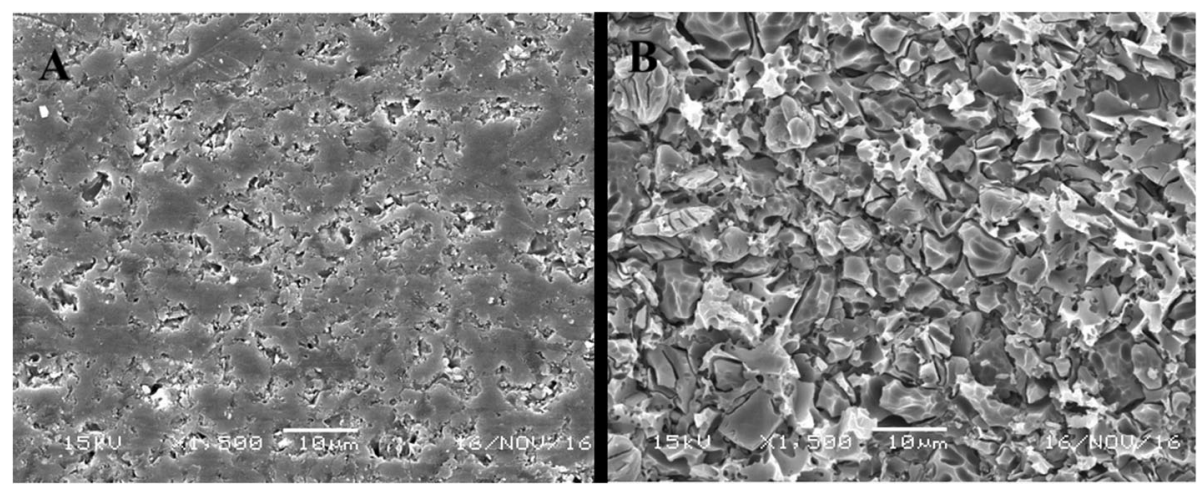

Fig. 3 SEM micrograph ( $\times 1500$ magnification) of $\mathbf{a}$ unetched and $\mathbf{b}$ HF-etched VE

considered the use of HF acid etching followed by the addition of silane, to be the bonding strategy of choice for $\mathrm{HC}$ materials.

\section{Conclusion}

Within the limitations of this study, the Universal Adhesives tested cannot be recommended as substitutes to the silanization of hybrid ceramic material.

\section{Abbreviations \\ CUB: Clearfil Universal Bond; HF: Hydrofluoric acid; MDP: 10- methacryloyloxydecyl dihydrogen phosphate; SEM: Scanning electron microscope; TNU: Tetric N-Bond Universal; UA: Universal adhesives; VE: Vita Enamic; $\mu$ TBS: Microtensile bond strength}

\section{Acknowledgments}

The authors are grateful to the Deanship of Scientific Research, King Saud University for funding through Vice Deanship of Scientific Research Chairs, Engr. Abdullah Bugshan research chair for Dental and Oral Rehabilitation (DOR).

\section{Authors' contributions}

MMA: prepared the basic study design and contributed in the writing of the article; LA: conducted data analysis, quality assessment; AAL: did sample preparation and characterization; RK: formatting and revision of the manuscript; NS: reviewed the manuscript; MMH: carried out the analysis; FA: revising and editing the manuscript and $\mathrm{AA}$ : provided general technical support and supervised the work. All authors have read and approved the manuscript, and ensure that this is the case.

\section{Funding}

This research work was funded by Deanship of Scientific Research, King Saud University for funding through Vice Deanship of Scientific Research Chairs, Engr. Abdullah Bugshan research chair for Dental and Oral Rehabilitation (DOR). Funding included materials used, testing tools, data analysis.

\section{Availability of data and materials}

All the data generated or analyzed during this study are included in this published article.

\section{Ethics approval and consent to participate}

Not Applicable.

\section{Consent for publication}

Not Applicable.

\section{Competing interests}

The authors declare that they have no competing interests.

\section{Author details}

1Department of Conservative Dental Sciences, College of Dentistry, Prince Sattam Bin Abdulaziz University, Alkharj 11942, Saudi Arabia. ${ }^{2}$ Preventive Dental Program, Ministry of Health, Riyadh 11179, Saudi Arabia. ${ }^{3}$ Department of Pediatric Dentistry and Orthodontics, College of Dentistry, King Saud University, Riyadh 11545, Saudi Arabia. ${ }^{4}$ Engineer Abdullah Bugshan research chair for Dental and Oral Rehabilitation, King Saud University, Riyadh 11545, Saudi Arabia. ${ }^{5}$ Dentistry, School of Medical Sciences, University of Manchester, Manchester, UK. ${ }^{6}$ Luminous Technical University College, Amman, Jordan. ${ }^{7}$ Department of Prosthodontics, College of Dentistry, Prince Sattam Bin Abdulaziz University, Alkharj 11942, Saudi Arabia. ${ }^{8}$ Department Of Restorative Dental Sciences, College of Dentistry, King Saud University, Riyadh 11545, Saudi Arabia.

Received: 12 February 2019 Accepted: 26 July 2019

Published online: 06 August 2019

\section{References}

1. Hickel R, Brushaver K, llie N. Repair of restorations--criteria for decision making and clinical recommendations. Dent Mater. 2013;29(1):28-50.

2. Ruse ND, Sadoun MJ. Resin-composite blocks for dental CAD/CAM applications. J Dent Res. 2014;93(12):1232-4.

3. Gracis S, Thompson VP, Ferencz JL, Silva NR, Bonfante EA. A new classification system for all-ceramic and ceramic-like restorative materials. Int J Prosthodont. 2015;28(3):227-35

4. Zimmermann M, Mehl A, Reich S. New CAD/CAM materials and blocks for chairside procedures. Int J Comput Dent. 2013;16(2):173-81.

5. Swain MV, Coldea A, Bilkhair A, Guess PC. Interpenetrating network ceramicresin composite dental restorative materials. Dent Mater. 2016;32(1):34-42.

6. Mormann WH, Stawarczyk B, Ender A, Sener B, Attin T, Mehl A. Wear characteristics of current aesthetic dental restorative CAD/CAM materials: two-body wear, gloss retention, roughness and martens hardness. J Mech Behav Biomed Mater. 2013;20:113-25.

7. Lawson NC, Bansal R, Burgess JO. Wear, strength, modulus and hardness of CAD/CAM restorative materials. Dent Mater. 2016:32(11):e275-83.

8. Fasbinder DJ, Neiva GF. Surface evaluation of polishing techniques for new resilient CAD/CAM restorative materials. J Esthet Restor Dent. 2016 28(1):56-66

9. Egilmez F, Ergun G, Cekic-Nagas I, Vallittu PK, Lassila LV. Light Transmission of Novel CAD/CAM Materials and Their Influence on the Degree of Conversion of a Dualcuring Resin Cement. Journal of Adhesive Dentistry. 2017;19(1):39-48

10. Chirumamilla G, Goldstein CE, Lawson NC. A 2-year retrospective clinical study of Enamic crowns performed in a private practice setting. J Esthet Restor Dent. 2016;28(4):231-7.

11. Guarda GB, Correr AB, Goncalves LS, Costa AR, Borges GA, Sinhoreti MA, Correr-Sobrinho L. Effects of surface treatments, thermocycling, and cyclic loading on the bond strength of a resin cement bonded to a lithium disilicate glass ceramic. Oper Dent. 2013;38(2):208-17.

12. Özcan $M$, Bernasconi M. Adhesion to zirconia used for dental restorations: a systematic review and meta-analysis. J Adhes Dent. 2015;17(1):7-26. 
13. Hooshmand T, Parvizi S, Keshvad A. Effect of surface acid etching on the biaxial flexural strength of two hot-pressed glass ceramics. J Prosthodont. 2008; 17(5):415-9

14. Marocho S, Ozcan M, Amaral R, Bottino M, Valandro L. Effect of resin cement type on the microtensile bond strength to lithium disilicate ceramic and dentin using different test assemblies. J Adhes Dent. 2013;15(4):361-8.

15. Awad MM, Alqahtani H, Al-Mudahi A, Murayshed MS, Alrahlah A, Bhandi SH. Adhesive bonding to computer-aided design/ computer-aided manufacturing esthetic dental materials: an overview. J Contemp Dent Pract. 2017;18(7):622-6.

16. Puppin-Rontani J, Sundfeld D, Costa AR, Correr AB, Puppin-Rontani RM, Borges GA, Sinhoreti M, Correr-Sobrinho L. Effect of Hydrofluoric Acid Concentration and Etching Time on Bond Strength to Lithium Disilicate Glass Ceramic. Operative Dentistry. 2017;42(6):606-15

17. Spitznagel FA, Horvath SD, Guess PC, Blatz MB. Resin bond to indirect composite and new ceramic/polymer materials: a review of the literature. J Esthet Restor Dent. 2014;26(6):382-93.

18. Matinlinna JP, Lassila LV, Özcan M, Yli-Urpo A, Vallittu PK. An introduction to silanes and their clinical applications in dentistry. International Journal of Prosthodontics. 2004;17(2):155-64.

19. Wagner A, Wendler M, Petschelt A, Belli R, Lohbauer U. Bonding performance of universal adhesives in different etching modes. J Dent. 2014:42(7):800-7.

20. Inokoshi M, Kameyama A, De Munck J, Minakuchi S, Van Meerbeek B. Durable bonding to mechanically and/or chemically pre-treated dental zirconia. J Dent. 2013;41(2):170-9.

21. Amaral M, Belli R, Cesar PF, Valandro LF, Petschelt A, Lohbauer U. The potential of novel primers and universal adhesives to bond to zirconia. J Dent. 2014;42(1):90-8.

22. de Lucena Pereiraa L, Camposb F. Dal Pivac AMdO, Gondimd LD, e Souzae ROdA, Özcanf M: can application of universal primers alone be a substitute for airborne-particle abrasion to improve adhesion of resin cement to zirconia? J Adhes Dent. 2015;17:169-74.

23. Makishi P, Andre CB, Silva JL, Bacelar-Sa R, Correr-Sobrinho L, Giannini M. Effect of storage time on bond strength performance of multimode adhesives to indirect resin composite and Lithium Disilicate glass ceramic. Oper Dent. 2016;41(5):541-51.

24. Kalavacharla VK, Lawson NC, Ramp LC, Burgess JO. Influence of etching protocol and Silane treatment with a universal adhesive on Lithium Disilicate bond strength. Oper Dent. 2015;40(4):372-8.

25. Tian T, Tsoi JK, Matinlinna JP, Burrow MF. Aspects of bonding between resin luting cements and glass ceramic materials. Dent Mater. 2014;30(7):e147-62.

26. Blatz MB. Bonding protocols for improved long-term clinical success. Compend Contin Educ Dent. 2014;35(4):276-7.

27. Aboushelib MN, Sleem D. Microtensile bond strength of lithium disilicate ceramics to resin adhesives. J Adhes Dent. 2014;16(6):547-52.

28. Della Bona A, Anusavice KJ, Mecholsky JJ Jr. Failure analysis of resin composite bonded to ceramic. Dent Mater. 2003;19(8):693-9.

29. Campos F, Almeida CS, Rippe MP, de Melo RM, Valandro LF, Bottino MA Resin bonding to a hybrid ceramic: effects of surface treatments and aging. Oper Dent. 2016;41(2):171-8.

30. Elsaka SE. Bond strength of novel CAD/CAM restorative materials to selfadhesive resin cement: the effect of surface treatments. J Adhes Dent. 2014; 16(6):531-40.

31. Ozcan M, Vallittu PK. Effect of surface conditioning methods on the bond strength of luting cement to ceramics. Dent Mater. 2003;19(8):725-31.

32. Della Bona A, Shen C, Anusavice KJ. Work of adhesion of resin on treated lithia disilicate-based ceramic. Dent Mater. 2004;20(4):338-44.

33. Lung CY, Matinlinna JP. Aspects of silane coupling agents and surface conditioning in dentistry: an overview. Dent Mater. 2012;28(5):467-77.

34. Yao C, Zhou L, Yang H, Wang Y, Sun H, Guo J, Huang C. Effect of silane pretreatment on the immediate bonding of universal adhesives to computer-aided design/computer-aided manufacturing lithium disilicate glass ceramics. Eur J Oral Sci. 2017;125(2):173-80.

35. Alrahlah A, Awad MM, Vohra F, Al-Mudahi A, Al jeaidi ZA, Elsharawy M. Effect of self etching ceramic primer and universal adhesive on bond strength of lithium disilicate ceramic. Journal of Adhesion Science and Technology. 2017;31(23):2611-9.

36. Blatz MB, Sadan A, Kern M. Resin-ceramic bonding: a review of the literature. J Prosthet Dent. 2003:89(3):268-74.
37. Amaral FL, Colucci V, PALMA-DIBB RG, Corona SA. Assessment of in vitro methods used to promote adhesive interface degradation: a critical review. J Esthet Restor Dent. 2007;19(6):340-53.

38. Roulet JF, Soderholm KJ, Longmate J. Effects of treatment and storage conditions on ceramic/composite bond strength. J Dent Res. 1995;74(1):381-7.

39. De Munck J, Van Landuyt K, Peumans M, Poitevin A, Lambrechts P, Braem $M$, Van Meerbeek B. A critical review of the durability of adhesion to tooth tissue: methods and results. J Dent Res. 2005;84(2):118-32.

40. Ikeda T, De Munck J, Shirai K, Hikita K, Inoue S, Sano H, Lambrechts P, Van Meerbeek $B$. Effect of air-drying and solvent evaporation on the strength of HEMA-rich versus HEMA-free one-step adhesives. Dent Mater. 2008;24(10): 1316-23.

41. Frankenberger $\mathrm{R}$, Hartmann VE, Krech M, Kramer N, Reich S, Braun A, Roggendorf M. Adhesive luting of new CAD/CAM materials. Int J Comput Dent. 2015;18(1):9-20.

42. Peumans M, Valjakova EB, De Munck J, Mishevska CB, Van Meerbeek B. Bonding effectiveness of luting composites to different CAD/CAM materials. J Adhes Dent. 2016;18(4):289-302.

43. Ozcan M, Volpato CA. Surface conditioning and bonding protocol for polymer-infiltrated ceramic: how and why? J Adhes Dent. 2016;18(2):174-5.

\section{Publisher's Note}

Springer Nature remains neutral with regard to jurisdictional claims in published maps and institutional affiliations.
Ready to submit your research? Choose BMC and benefit from:

- fast, convenient online submission

- thorough peer review by experienced researchers in your field

- rapid publication on acceptance

- support for research data, including large and complex data types

- gold Open Access which fosters wider collaboration and increased citations

- maximum visibility for your research: over $100 \mathrm{M}$ website views per year

At $\mathrm{BMC}$, research is always in progress.

Learn more biomedcentral.com/submissions 